and psychology might in that case be poised for an important conceptual revolution and for fundamental empirical advances. Arbib has selected some of the right general topics, and some of the right substantive material, and many of the ideas that he treats are both interesting and important. However, I have some doubt as to whether the degree of enlightenment he sheds will exceed the amount of mystification. This may seem rather harsh since many of these problems, because of their fragmentary development, are as yet very obscure. Maybe some of the issues which are raised here are too difficult to give any scientific account of at present, even though we can recognize their importance and can see occasional glimmerings of understanding here and there. In this case Arbib may well be justified in flying a few kites in an attempt to get people thinking.

Finally, it is impossible to resist the temptation to mention the quirk which has been adopted in this book of using exclusively the female form of third person pronouns: "it gives the reader all she needs in system theory", and so on. If Michael Arbib means this as a gesture of male solidarity with women's liberation she might have been more appreciated by members of that movement had she written a rather more comprehensible account.

\section{Keith OATLEy}

\section{History of Hydraulics}

Hydraulic Power. By Ian McNeil. Pp. ix + 197. (Longman: London, November 1972.) £3.75.

IN Mr Ian McNeil's book Hydraulic Power, one of the Industrial Archaeology Series edited by L. T. C. Rolt for Longmans, the author has had two objectives in view. His prime object has been to give a short account of the history of hydraulic power, beginning with the early inventors Pascal and Bramah, and progressing through Arm. strong, Tweddell and Ellington to HeleShaw, Beacham, Constantinesco, Sinclair, Dowty and Ferguson to reach the present state of knowledge. From 1930 onward hydraulic power experienced a kind of renaissance, particularly through the development of nitrile rubber, a material with physical properties exactly fulfilling the requirements for seals and packings of hydraulic components. His second object is to survey this field for the industrial archaeologist.

The book covers a good deal of ground, dealing with a number of different topics that nowadays would be unlikely to be found together between two covers, even in a book on the history of energy. It is interesting to read, but lacks conciseness. It wanders from one subject to another. The chapter head ings have no standard of parity, em. phasizing this desultory treatment. Some of the illustrations are not very clearfor example, Armstrong's rotary hydraulic machine of 1838--whereas a few, such as that of Elisha Otis's safety lift, are quite fascinating.

A number of interesting schemes that have since been abandoned are con. sidered-for example, Constantinesco's wave transmission. The most noteworthy sections include chapter 7 , deal. ing with hydraulic mains systems, municipal and metropolitan, and drawing attention to the fact that a great many of these networks are still in existence and in daily use. Chapter 8, "Cranes, Hoists and Lifts", reminds us of the lead taken over by the USA in many large scale projects from 1866 onwards, which led to its primacy later in the mining and construction industries. Also interesting is the section on fluid coupling and torque converter (chapter 11), though here the description would be much clearer with the addition of a diagram. Chapter 12, "Twentieth Century Renaissance", pinpoints the part that many small improvements have played in this regard.

In promoting his second objective, the author has interpolated the views of the industrial archaeologist throughout the book, and has carefully described a great many of the earlier hydraulic machines, with their auxiliary apparatus, pumphouses, etc., many of which are still working, or have been preserved by museums or other agencies. He gives careful directions to sites where they can be seen, and a short gazetteer completes the book. This information is important and valuable, both as a record of the machines and as a welcome source of reference for the industrial archaeologist.

Aubrey Burstall

\section{Moseley and the Elements}

Moseley and the Numbering of the Elements. By Bernard Jaffe. Pp. $\mathrm{x}+$ 263. (Heinnemann: London, November 1972.) $£ 1.50$.

IT is always interesting to ask what opinion the biographee would form of his biography. In this case one can, I think, be quite certain of the answer: Moseley would have held this work in contempt. Jaffe writes in his preface of "writing a full biography" and appends a "Complete List of Research Papers by Moseley"; he implies that he has spent ten years gathering material and thanks nearly thirty persons, including a score of Moseley's acquaintances, for aiding his researches; he has found in the archives and quotes at length (though not always in full) the known letters from Moseley to Rutherford, C. G. Darwin, and N. Bohr. But this material, which apart from the letters proves to be negligible, is then folded into a pabulum of romanticized science digested to gibberish for consumption by pre-adolescents. There are sections -for example that on the discovery of the diffraction of X-rays by crystals ("chapter 4. Moseley is Stirred by the Crystal Gazers")-which may be taken as veritable paradigms for wanton carelessness of factual accuracy and traduction of physical principles. This slough of confusion (as to genre and audience as well) was originally published as one of the paperbacks in the "Science Study Series" intended as supplementary readings for a distinguished American secondary school physics course. It here appears in its British edition between hard covers at twice the American price but without the collection of plates in the original.

In his preface Jaffe rues his failure to turn up the very extensive collection of letters which Moseley wrote to his mother and sister, recognizing perhaps that only they would give the record of Moseley's experiences, activities, and personality upon which an adequate biography could be based. But these letters have in fact come to light; together with Moseley's scientific correspondence they have now been edited and annoted by John L. Heilbron: H. G. J. Moseley : The Life and Letters of an English Physicist, 1887-1914 (University of California Press, Berkeley, in the press). It is to Heilbron's scholarly study that anyone with a serious interest in Moseley and the numbering of the elements will have to turn.

\section{Paul Forman}

\section{Unifying Principles}

Statistical Mechanics: New Concepts, New Problems, New Applications. Edited by S. A. Rice, K. F. Freed, and J. C. Light. (Proceedings of the Sixth IUPAP Conference on Statistical Mechanics.) Pp. viii +423. (University of Chicago: London and Chicago, 1972.) $£ 7.20$.

THE conference that brings active workers in related disciplines together is rightly becoming fashionable. We have here twenty-one papers ranging over statistical mechanics and the related fields of hydrodynamics and cybernetics given in March/April 1971. A glance at the list of distinguished contributors shows that it must have been very enjoyable indeed to listen to their interactions, some of the flavour of which has been preserved by recording the discussions after each paper. For example, it emerged that, rather disgracefully, very little is known in general about the limiting behaviour of equilibrium properties near absolute zero temperature, which is a little surprising when one considers all the work that has gone into studies of ground and low-lying states of particular systems. 